\title{
Propofol Protects against Ischemia/Reperfusion Injury Associated with Reduced Apoptosis in Rat Liver
}

\author{
Ali F. Abdel-Wahab ${ }^{1,2}$ and Wahid M. Al-Harizy ${ }^{3}$ \\ ${ }^{1}$ Pharmacology Department, Faculty of Medicine, Cairo University, Giza, Egypt \\ ${ }^{2}$ Umm Al-Qura University, Makkah, Saudi Arabia \\ ${ }^{3}$ Biochemistry Department, Faculty of Medicine, Cairo University, Giza, Egypt \\ Correspondence should be addressed to Ali F. Abdel-Wahab; alifatehi@hotmail.com
}

Received 5 June 2013; Accepted 8 July 2013

Academic Editors: A. Mizutani, A. Pedoto, and A. Wiebalck

Copyright (c) 2013 A. F. Abdel-Wahab and W. M. Al-Harizy. This is an open access article distributed under the Creative Commons Attribution License, which permits unrestricted use, distribution, and reproduction in any medium, provided the original work is properly cited.

\begin{abstract}
Propofol is an intravenous anesthetic, reported to have a protective effect against ischemia/reperfusion (I/R) injury in heart and brain, but no definite data are available concerning its effect in hepatic I/R. This work investigated the effect of propofol anesthesia on hepatic I/R injury using in vivo rat model. Four groups of rats were included: sham operated, I/R ( 30 min ischemia and $2 \mathrm{~h}$ reperfusion), I/R treated with propofol $(10 \mathrm{mg} / \mathrm{kg} / \mathrm{h})$, and I/R treated with propofol $(20 \mathrm{mg} / \mathrm{kg} / \mathrm{h})$. Liver enzyme leakage, TNF$\alpha$ and caspase-3 levels, and antiapoptotic Bcl-xL/apoptotic Bax gene expression, together with histopathological changes, were used to evaluate the extent of hepatic I/R injury. Compared with sham-operated group, I/R group showed significant increase in serum levels of liver enzymes (ALT, AST), TNF- $\alpha$, and caspase- 3 and significant decrease in the Bcl-xL/Bax ratio, associated with histopathologic damage in liver. Propofol infusion significantly attenuated these changes with reduced hepatic histopathologic lesions compared with nonpreconditioned I/R group. However, no significant differences were found between two groups treated with different doses of propofol. In conclusion, propofol infusion reduced hepatic I/R injury with decreased markers of cellular apoptosis. Therefore, propofol anesthesia may provide a useful hepatic protection during liver surgery.
\end{abstract}

\section{Introduction}

Liver ischemia/reperfusion (I/R) injury is a common pathophysiological process prevalent in hepatic transplant surgery, partial hepatectomy, and shock conditions. Liver failure induced by $\mathrm{I} / \mathrm{R}$ is the most serious complication with a direct impact on prognosis of the disease and even causes deaths [1]. This accounts for about $80 \%$ of liver transplant failures and the high mortality rate after partial hepatectomy [2]. Several mechanisms interact during I/R to cause liver damage and death of liver cells, including the direct ischemic cellular damage as well as cell injury due to activation of inflammatory response after reperfusion [1].

Apoptosis is recognized as the key feature of cell death in the ischemic liver [3]. Apoptosis (programmed cell death) is an active process characterized by cell shrinkage, chromatin condensation, nuclear fragmentation, and formation of apoptotic bodies [4]. On the other hand, necrosis is passive and characterized by cell swelling, rupture of the plasma membrane, and cell lysis, with leakage of cytoplasmic components [5]. Cellular apoptosis was shown to be mediated by a family of cysteine aspartate (caspases) caspase- 1 to caspase14. The poly (ADP-ribose) polymerase (PARP), a nuclear enzyme involved in DNA repair, is a well-known substrate for caspase-3 cleavage, playing a key role in apoptotic cell death [6]. Also, the Bcl-2 family of proteins functions as important regulators of apoptosis. It consists of two classes: antiapoptotic genes, such as $\mathrm{Bcl}-\mathrm{xL}$ and $\mathrm{Bcl}-2$, proven to promote survival, and proapoptotic genes including Bad and Bax, which oppose survival function [4]. Indeed, the ratio between these two subsets, antiapoptotic and proapoptotic genes, determines the susceptibility of cells to a death signal [7]. Moreover, the inflammatory cytokine tumor necrosis factor alpha (TNF- $\alpha$ ) has been incriminated in pathogenesis of hepatic I/R injury [8], where it may exacerbate hepatic cellular apoptosis [9]. 
Propofol (2,6-diisopropyl phenol), a fast short-acting intravenous anesthetic, has been widely used clinically for anesthesia and for sedation of ICU patients. Total intravenous anesthesia (TIVA) with propofol is widely used during liver transplantation because its metabolism is not greatly affected by liver failure [10]. Propofol does not adversely affect hepatic and renal functions as long as hepatic and renal blood flows are maintained [11]. Propofol is known to have antioxidant activity, protecting against lipid peroxidation [12]. Consistent with its activity as an antioxidant, propofol has been reported to have a protective effect against I/R injury in several organs, such as brain [13] and heart [14], as well as in the lower limbs [15]. In the liver, there is no evidence for a protective effect of propofol on I/R injury in vivo, and the evidence in vitro using rat liver slices suggested that propofol does not have hepatoprotective effects [16].

Recently, propofol infusion was shown to attenuate hepatic I/R injury in vivo in rabbits [17]. However, considering the limited number of reports, the effect of propofol on the liver during I/R injury remains controversial. Our hypothesis is that propofol, by increasing liver resistance to I/R injury, could improve liver function during recovery after liver surgery and reduce the postoperative morbidity. The purpose of this study was to elucidate the possible hepatoprotective and antiapoptotic effects of propofol in an in vivo rat model of hepatic I/R injury.

\section{Materials and Methods}

2.1. Animals. Eighty adult male Wistar rats, weighing 220$280 \mathrm{~g}$, were purchased from the animal care unit of Kasr AlAini Faculty of Medicine, Cairo University. Animals were housed four to a cage in a constant temperature $\left(22-24^{\circ} \mathrm{C}\right)$ and light-controlled room on an alternating 12:12-h light/dark cycle and had free access to food and water ad libitum. All rats were fasted for $12 \mathrm{~h}$ before surgical intervention. Experiments were conducted according to ethical norms approved by local ethics committee for care and use of laboratory animals.

2.2. Experimental Design and Propofol Infusion. Rats were anesthetized with intraperitoneal injection of sodium pentobarbital $(35 \mathrm{mg} / \mathrm{kg})$. After a suitable level of anesthesia had been attained, the femoral vein was exposed and cannulated to establish a venous line for infusion of maintenance anesthesia. Animals were divided, according to the infused IV anesthetic agent, into four groups ( $n=20$ /group):

Group 1: sham operation and anesthesia maintained with pentobarbital $(5 \mathrm{mg} / \mathrm{kg} / \mathrm{h})$;

Group 2: hepatic I/R and anesthesia maintained with pentobarbital $(5 \mathrm{mg} / \mathrm{kg} / \mathrm{h})$;

Group 3: hepatic I/R and anesthesia maintained with propofol $(10 \mathrm{mg} / \mathrm{kg} / \mathrm{h})$;

Group 4: hepatic I/R and anesthesia maintained with propofol (20 mg/kg/h).

Propofol (2,6 diisopropylphenol, Diprivan 1\% injectable emulsion $10 \mathrm{mg} / \mathrm{mL}$ ) was obtained from AstraZeneca Corps
(Milan, Italy). Propofol was given by continuous IV infusion soon after femoral venous cannulation and continued throughout the experimental period.

2.3. Hepatic Ischemia-Reperfusion. Hepatic ischemia was induced after $30 \mathrm{~min}$ of starting anesthetic infusion to allow for stabilization of the animal model. A midline abdominal incision was made and the perihepatic ligament freed to reveal the hepatic pedicle. A rat model of partial, rather than total, hepatic I/R was used as previously described [17, 18]. Briefly, a noncrushing microvascular clamp was placed across all structures (hepatic artery, portal vein, and bile duct) leading to the left and median liver lobes ( $70 \%$ of liver mass) and occlusion is maintained for 30 minutes. Reperfusion was initiated by removal of the clamp to restore the hepatic flow and the animals were observed during reperfusion for 2 hours. The body temperature was monitored and maintained at $37 \pm 0.4^{\circ} \mathrm{C}$ by a heating lamp and warm sterile moistened gauze placed over the laparotomy to avoid dehydration. This method induced a severe ischemic insult to the liver, confirmed by the pale blanching of ischemic lobes, but allows portal decompression through the right and caudate lobes and thus prevents mesenteric venous congestion.

Sham-operated control animals received equivalent anesthesia and underwent laparotomy and manipulation of liver hilum but without vascular occlusion.

2.4. Laboratory Works. At the end of experiments, $2 \mathrm{~h}$ after reperfusion, blood samples were drawn directly from the IVC with a syringe and rats being then sacrificed by decapitation.

Blood samples were immediately centrifuged at $3,000 \mathrm{rpm}$ for $10 \mathrm{~min}$. The separated serum was used to measure liver enzymes (ALT and AST), serum TNF- $\alpha$, and caspase-3 levels.

Liver samples were removed immediately after sacrifice from all groups and used for detection of Bcl-xL and Bax gene expression in the liver tissues, in addition to histopathological examination.

2.4.1. Analysis of Liver Enzymes. Serum alanine aminotransferase (ALT) and aspartate aminotransferase (AST) levels were determined with a Hitachi 911 automatic analyzer (Boehringer Mannheim, Germany).

2.4.2. Assay for Tumor Necrosis Factor Alpha (TNF- $\alpha$ ). Blood levels of TNF- $\alpha$ were measured by enzyme-linked immunosorbent assay (ELISA) using commercially available kits according to the manufacturer's instructions (Quantikine HS; R \& D Systems, Minneapolis, MN, USA). The color intensity of the enzymatic indicator reaction was measured photometrically at $450 \mathrm{~nm}$ in an ELISA plate reader, with a minimum detectable level $0.5 \mathrm{pg} / \mathrm{mL}$.

2.4.3. Measurement of Serum Caspase-3. Quantitative determination of serum caspase- 3 was measured using CorrelateAssay, Caspase-3 Colorimetric Assay Kit, (Catalog no. 907013). It involves conversion of a specific chromogenic substrate for caspase- 3 followed by colorimetric detection of colored end-product (p-nitroaniline, $\mathrm{p}$-NA) whose absorbance 
is directly proportional to the respective caspase- 3 concentration. Using linear graph paper, the average net nominal concentration for each standard was plotted versus actual concentration of caspase- 3 for the standards. The concentration of caspase-3 $(\mathrm{U} / \mathrm{mL})$ in samples can be determined from appropriate standard curve.

\subsubsection{Detection of Liver Bcl- $x L$ and Bax Gene Expression}

RNA Extraction. Total RNA was extracted from liver tissue by the acid guanidinium thiocyanate-phenol-chloroform method [19]. RNA content and purity were measured by a UV spectrophotometer.

Reverse Transcription-Polymerase Chain Reaction. For amplification of the targets genes, reverse transcription and polymerase chain reaction (PCR) were run in two separate steps. Briefly, reaction mixture of RT reaction containing $1 \mu \mathrm{g}$ total RNA, $0.5 \mu \mathrm{g}$ random primer, $5 \times$ RT buffer, $2.5 \mathrm{mmol} / \mathrm{L}$ dNTP, 20 U RNase inhibitor, and 200 U MMLV reverse transcriptase in a total volume of $25 \mu \mathrm{L}$ was incubated at $37^{\circ} \mathrm{C}$ for $60 \mathrm{~min}$ and then heated to $95^{\circ} \mathrm{C}$ for $5 \mathrm{~min}$ to inactivate MMLV.

PCR was carried out with $1.5 \mu \mathrm{L}$ RT products, $10 \times$ PCR buffer (without $\mathrm{Mg}^{2+}$ ) $2.5 \mu \mathrm{L}, 2.0 \mu \mathrm{L}$ dNTP $(2.5 \mathrm{mmol} / \mathrm{L}$ ), $2.0 \mu \mathrm{L} \mathrm{MgCl}_{2}(25 \mathrm{mmol} / \mathrm{L}), 0.5 \mu \mathrm{L}$ each primer $(20 \mu \mathrm{mol} / \mathrm{L})$ of $\beta$-actin, $0.5 \mu \mathrm{L}$ each primer of gene to be tested $(20 \mu \mathrm{mol} / \mathrm{L})$, and $1 \mathrm{U}$ of Taq DNA polymerase (Promega Corp.), in a final volume of $25 \mu \mathrm{L}$. Thermal cycler conditions were as follows: a first denaturing cycle at $97^{\circ} \mathrm{C}$ for $5 \mathrm{~min}$, followed by a variable number of cycles of amplification defined by denaturation at $96^{\circ} \mathrm{C}$ for $1.5 \mathrm{~min}$, annealing for $1.5 \mathrm{~min}$, and extension at $72^{\circ} \mathrm{C}$ for $3 \mathrm{~min}$. A final extension cycle of $72^{\circ} \mathrm{C}$ for $15 \mathrm{~min}$ was included. The primer for $\mathrm{Bcl}-\mathrm{xL}$ was forward: $5^{\prime}$-GGAGGGCACTTCCTGG- $3^{\prime}$ and reverse: $5^{\prime}$-GCCTGGCATCACGAC- $3^{\prime}$, and for Bax was forward: $5^{\prime}$-CTGAGCTGACCTTGGAGC- $3^{\prime}$ and reverse: $5^{\prime}$-GACTCCAGCCACAAAGATG- ${ }^{\prime}$. mRNA levels were normalized by the $\beta$ actin values in the samples. $\beta$-Actin primer was forward: $5^{\prime}$-TGTTGTCCCTGTATGCCTCT- $3^{\prime}$ and reverse: $5^{\prime}$-TAATGTCACGCACGATTTCC-3'.

Agarose Gel Electrophoresis. All PCR products were electrophoresed on $2 \%$ agarose stained with ethidium bromide and visualized by UV transilluminator.

Semiquantitative Determination of PCR Products. Semiquantitation was performed using the gel documentation system (BioDO, Analyser) supplied by Biometra. According to the following amplification procedure, relative expression of each studied gene $(\mathrm{R})$ was calculated following the formula: $\mathrm{R}$ $=$ densitometric units of each studied gene/densitometrical units of $\beta$-actin.

2.4.5. Histopathologic Examinations. Left hepatic lobe specimens from all rats were fixed in $10 \%$ buffered formalin and embedded in paraffin. Sections of $5 \mu \mathrm{m}$ depth were stained with hematoxylin-eosin (H-E) and examined using light microscopy. Five sections were examined for ten random fields for each liver and evaluated by an independent pathologist unaware of the experimental groups. Hepatic integrity was evaluated for presence and extent of reactive changes (sinusoidal congestion, hepatocellular fatty changes, and cytoplasmic vacuolation) (none $=0$, zone III $=1$, zone II-III $=2$, zone I-II-III panacinar $=3$ ) and cellular necrosis (none $=0$, single cell or focal (zone I) $=1$, submassive necrosis (bridging necrosis) $=2$, bridging necrosis + massive necrosis + infarction $=3$ ). These parameters were combined into a table, and a semiquantitative scale was used [20].

2.5. Data Analysis. All data are expressed as mean \pm SEM. Results were analyzed using SPSS computer software package version 10.0 (Chicago, IL, USA). Multiple groups were compared using one-way analysis of variance (ANOVA) followed by post hoc Kruskal-Wallis and Mann-Whitney $U$ tests. Simple pairwise comparisons were performed using Student's $t$-test where appropriate. Differences of $P<0.05$ were considered statistically significant.

\section{Results}

3.1. Effect on Liver Functions. Serum levels of the liver enzymes, alanine aminotransferase (ALT) and aspartate aminotransferase (AST), were significantly elevated in I/R group compared with the sham-operated group $(87 \pm 6.8$ and $134 \pm 9.5 \mathrm{U} / \mathrm{L}$ versus $28 \pm 2.2$ and $53 \pm 4.9 \mathrm{U} / \mathrm{L}$, respectively, $P<$ $0.01)$. Serum ALT and AST levels were significantly reduced in both propofol preconditioned I/R groups compared with those in the nonpreconditioned I/R group $(P<0.05)$, which indicates that both doses of propofol produce similar improvement in liver function (Table 1 and Figure 1).

3.2. Effect on Tumor Necrosis Factor Alpha (TNF- $\alpha$ ). The concentrations of proinflammatory cytokine TNF- $\alpha$ were significantly increased in I/R group compared with shamoperated group $(189.2 \pm 16.8$ versus $62.5 \pm 4.1 \mathrm{pg} / \mathrm{mL}$, $P<0.01)$. These TNF- $\alpha$ levels were significantly reduced by propofol infusion $(P<0.05)$, with significantly lower levels produced by the higher propofol dose $(20 \mathrm{mg} / \mathrm{kg} / \mathrm{h})$ compared with those observed in the group treated by the low dose $(10 \mathrm{mg} / \mathrm{kg} / \mathrm{h})(88.5 \pm 6.9$ versus $112.4 \pm 9.2 \mathrm{pg} / \mathrm{mL}$, $P<0.05$ ) (Table 1 and Figure 2).

3.3. Effect on Caspase-3 Levels. The serum levels of caspase3 were significantly increased in I/R group compared with sham-operated group $(783.2 \pm 51.6$ versus $491.8 \pm 34.3 \mathrm{U} / \mathrm{mL}$, $P<0.05)$. The elevated caspase-3 levels were significantly reduced similarly by the two doses of propofol $(P<0.05)$, indicating a similar effect on this important indicator of cellular apoptosis by both doses of propofol (Table 1 and Figure 3).

3.4. Effect on mRNA of Bcl-xL and Bax in Liver Tissues. Exposure of rats to I/R leads to significant decrease in the antiapoptotic Bcl-xL gene expression and significant increase in the proapoptotic Bax gene expressions following $2 \mathrm{~h}$ of reperfusion. These changes resulted in significant decrease 
TABLE 1: Changes in studied parameters (serum levels of ALT, AST, TNF- $\alpha$, and caspase-3), hepatic tissue expression of Bcl-xL and Bax genes, and histopathological changes of liver in different groups.

\begin{tabular}{|c|c|c|c|c|}
\hline & Sham & $\mathrm{I} / \mathrm{R}$ & I/R propofol 10 & I/R propofol 20 \\
\hline \multicolumn{5}{|l|}{ Serum levels } \\
\hline $\operatorname{ALT}(\mathrm{U} / \mathrm{L})$ & $28 \pm 2.2$ & $87 \pm 6.8^{*}$ & $59 \pm 5.4^{\dagger}$ & $51 \pm 5.2^{\dagger}$ \\
\hline AST (U/L) & $53 \pm 4.9$ & $134 \pm 9.5^{*}$ & $81 \pm 7.2^{\dagger}$ & $76 \pm 7.3^{\dagger}$ \\
\hline TNF- $\alpha(\mathrm{pg} / \mathrm{mL})$ & $62.5 \pm 4.1$ & $189.2 \pm 16.8^{*}$ & $112.4 \pm 9.2^{\dagger}$ & $88.5 \pm 6.9^{\dagger \ddagger}$ \\
\hline Caspase- $3(\mathrm{U} / \mathrm{mL})$ & $491.8 \pm 34.3$ & $783.2 \pm 51.6^{*}$ & $579.4 \pm 47.2^{\dagger}$ & $546.1 \pm 43.1^{\dagger}$ \\
\hline \multicolumn{5}{|c|}{$\mathrm{Bcl}-\mathrm{xL}$ and Bax gene expression in liver tissue } \\
\hline Bcl-xL/Bax ratio & $3.4 \pm 0.6$ & $0.41 \pm 0.2^{*}$ & $1.3 \pm 0.4^{\dagger}$ & $1.8 \pm 0.3^{\dagger}$ \\
\hline \multicolumn{5}{|c|}{ Histopathological changes of liver } \\
\hline Reactive changes & $0.1 \pm 0.03$ & $4.2 \pm 0.3^{*}$ & $2.5 \pm 0.1^{\dagger}$ & $2.1 \pm 0.08^{\dagger}$ \\
\hline Cellular necrosis & $0.0 \pm 0.0$ & $0.9 \pm 0.04^{*}$ & $0.4 \pm 0.06^{\dagger}$ & $0.3 \pm 0.05^{\dagger}$ \\
\hline
\end{tabular}

Data are presented as mean \pm SEM.

$*$ : significant change compared to sham-operated group.

$\dagger$ : significant change compared to I/R group.

‡: significant change compared to low propofol dose.

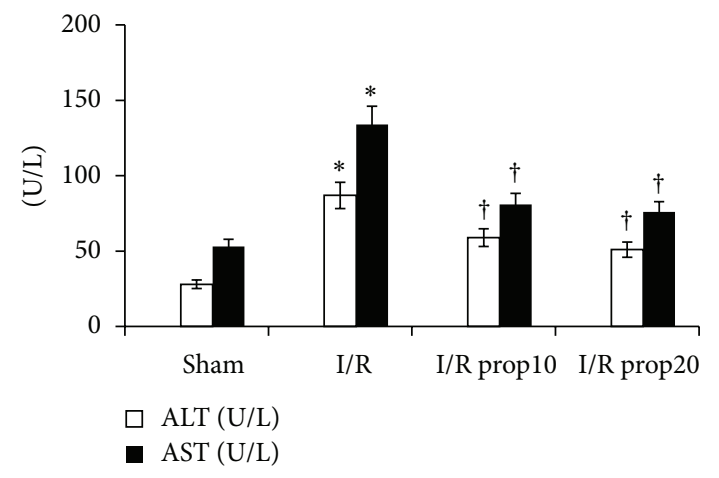

FIgURE 1: Serum levels of liver enzymes, ALT and AST, were significantly elevated in I/R group compared with sham-operated group $(P<0.01)$. Both ALT and AST levels were significantly reduced by propofol infusion at both doses $(P<0.05) .{ }^{*}$ Significant change compared to sham group, ${ }^{\dagger}$ significant change compared to I/R group.

in the $\mathrm{Bcl}-\mathrm{xL} / \mathrm{Bax}$ ratio in $\mathrm{I} / \mathrm{R}$ group compared with shamoperated group $(0.41 \pm 0.2$ versus $3.4 \pm 0.6, P<0.001)$, which reflects a change in the balance between cell life- and deathpromoting genes. By analyzing the effect of propofol on the expression of different genes involved in apoptosis, we found that propofol infusion, at both doses, leads to upregulation of the antiapoptotic $\mathrm{Bcl}-\mathrm{xL}$ gene expression and downregulation of the proapoptotic Bax gene expression, with significant increase in the $\mathrm{Bcl}-\mathrm{xL} / \mathrm{Bax}$ ratio in the propofol preconditioned I/R groups compared with the nonpreconditioned I/R group $(P<0.05)$. Although high dose of propofol showed higher $\mathrm{Bcl}-\mathrm{xL} / \mathrm{Bax}$ ratio than low dose, the difference was not statistically significant $(1.8 \pm 0.3$ versus $1.3 \pm 0.4, P>0.05)$, suggesting that the observed antiapoptotic effect of propofol is not dose dependent (Table 1 and Figure 4).

3.5. Effect on Pathological Changes in the Liver. As revealed in Figure 6, histopathological examination showed normal

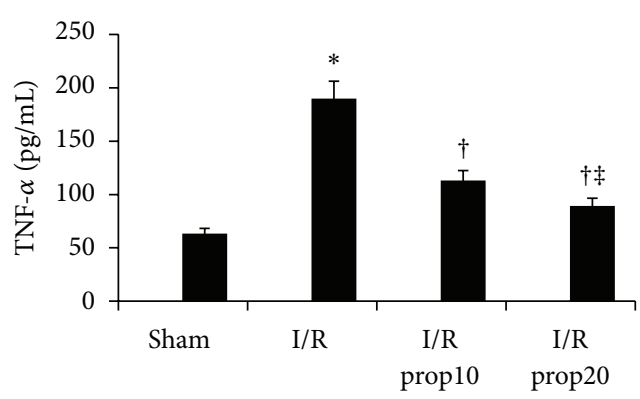

FIGURE 2: Serum levels of TNF- $\alpha$ were significantly increased in I/R group compared with sham-operated group $(P<0.01)$. TNF$\alpha$ levels were significantly reduced by propofol infusion $(P<$ $0.05)$, and the reduction was more marked with higher dose $(P<$ $0.05)$. ${ }^{*}$ Significant change compared to sham group, ${ }^{\dagger}$ significant change compared to I/R group, ${ }^{*}$ significant change compared to low propofol dose.

architecture of hepatic lobules in sham-operated control group, while in I/R group the evaluation revealed evident hepatic lesions in the form of sinusoidal congestion, hepatocellular fatty changes, and cytoplasmic vacuolation, together with area of focal and bridging necrosis. These changes were markedly attenuated in both groups treated with propofol (10 or $20 \mathrm{mg} / \mathrm{kg} / \mathrm{h}$ ), showing scores of hepatic injury (reactive changes and necrosis) significantly lower than those observed in the nonpreconditioned I/R group $(P<0.01)$, with no significant difference between the two doses of propofol $(P>$ 0.05) (Table 1 and Figure 5).

\section{Discussion}

Propofol was shown to have protective effect in myocardial and neuronal I/R but no definite data available concerning the potential benefit of total anesthesia with propofol in hepatic surgery. This study examined the hepatoprotective effect of propofol infusion in a rat model of I/R injury. Data presented 


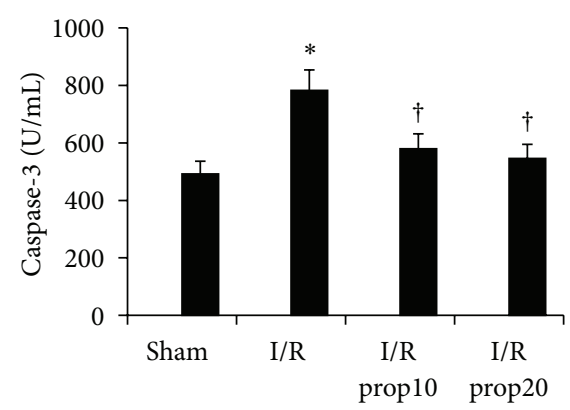

FIgURE 3: Serum levels of caspase-3 were significantly increased in $\mathrm{I} / \mathrm{R}$ group compared with sham-operated group $(P<0.05)$. The caspase-3 levels were significantly reduced by propofol infusion at both doses $(P<0.05)$. * Significant change compared to sham group, ${ }^{\dagger}$ significant change compared to I/R group.

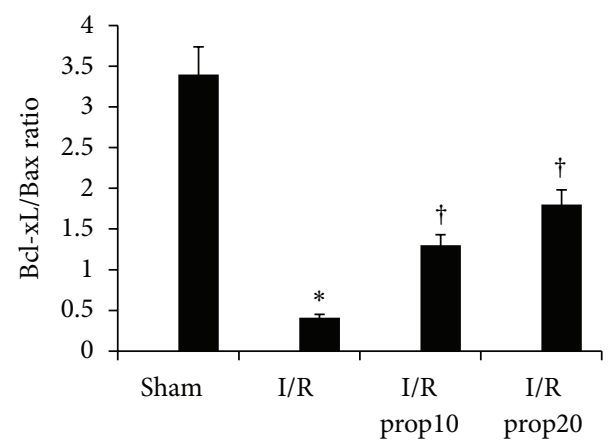

Figure 4: The Bcl-xL and Bax gene expression in liver tissue expressed as $\mathrm{Bcl}-\mathrm{xL} / \mathrm{Bax}$ ratio was markedly decreased in I/R group compared with sham-operated group $(P<0.001)$. Propofol infusion, at both doses, significantly increased the $\mathrm{Bcl}-\mathrm{xL} / \mathrm{Bax}$ ratio $(P<$ 0.05 ) by the upregulation of Bcl-xL gene and the downregulation of the Bax gene expression. * Significant change compared to sham group, ${ }^{\dagger}$ significant change compared to I/R group.

here demonstrates that intravenous infusion of propofol at both doses 10 and $20 \mathrm{mg} / \mathrm{kg} / \mathrm{h}$, starting before the ischemic insult, can confer liver protection against $I / R$ injury with modulation of cellular apoptosis.

The partial hepatic ischemia for $30 \mathrm{~min}$ followed by $2 \mathrm{~h}$ reperfusion used in this study has been described by several investigators $[8,17,18]$. Rats exposed to this form of $\mathrm{I} / \mathrm{R}$ showed significant increase in serum levels of liver enzymes (ALT and AST), associated with correspondent microscopic pathological alterations in liver tissues with area of focal and bridging necrosis. Previous results showed that partial hepatic I/R resulted in damage in both ischemic and nonischemic liver [21]. Although nonischemic liver did not undergo an ischemic event, circulating ROS may have played a role in the injury of nonischemic liver [22]. It has been found that partial hepatic ischemia for $45 \mathrm{~min}$ followed by 1 and $3 \mathrm{~h}$ of reperfusion leads to marked elevation of the levels of transaminases, ALT and AST, in the rat model of I/R compared with the sham-operated group [23].

Current results demonstrated that exposure of rats to I/R induced initiation of the apoptotic pathways as revealed

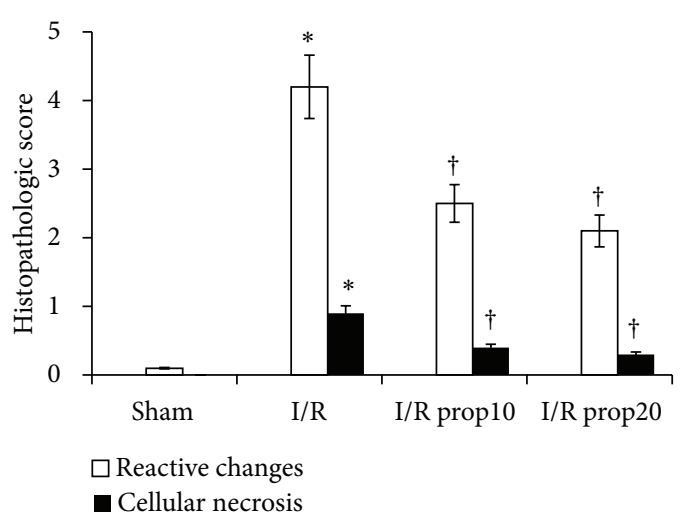

FIgURE 5: Histopathological evaluation of liver lesions revealed reactive changes (congestion, fatty change, and cytoplasmic vacuolation) and cellular necrosis, with high score in I/R group. The hepatic injury score was significantly reduced in both propofol-treated groups compared with the nonpreconditioned I/R group $(P<0.01)$. ${ }^{*}$ Significant change compared to sham group, ${ }^{\dagger}$ significant change compared to I/R group.

by the significant increase in the proinflammatory cytokine TNF- $\alpha$ levels and increased activity of caspase-3, together with shifting of the Bcl-xL/Bax ratio towards increased proapoptotic Bax gene expression. Such apoptosis is probably triggered by mitochondrial permeability transition and reactive oxygen species (ROS) released by activated Kupffer cells [21]. This leads to release of mitochondrial cytochrome c and activates caspase- 9 which, in turn, activates caspase 3, the initiator of the final execution stages of nuclear apoptosis [24]. These results are in accordance with those obtained by Hartkorn et al., [25], who observed decreased expression of the antiapoptotic gene Bcl-xL following hepatic ischemia in rat liver and attributed this to the suppressing effect of released ROS.

It is also proposed that inflammatory cytokines, such as TNF- $\alpha$, are involved in the massive hepatocellular apoptosis occurring after reperfusion [9]. TNF receptor 1 (TNF-R1) is connected to a cytoplasmatic region called "death domain," which activates specific caspases with subsequent release of mitochondrial proteins, leading to degradation of the chromosomal DNA and cell death [26]. Increased serum TNF- $\alpha$ levels have been documented after reperfusion in a rat model of hepatic ischemia, and the levels correlated with the duration of ischemia [8]. In addition, the application of anti-TNF$\alpha$ serum has been shown to reduce serum transaminase levels after hepatic ischemia. Thus, TNF- $\alpha$ was considered as a crucial inducer of apoptotic cell death in the ischemic liver [27].

In this study, infusion with propofol, 10 or $20 \mathrm{mg} / \mathrm{kg} / \mathrm{h}$, starting $30 \mathrm{~min}$ before the beginning of ischemia in our rat model significantly decreased leakage of liver enzymes, reduced TNF- $\alpha$ and caspase-3 levels, shifted the Bcl-xL/Bax ratio towards the apoptosis inhibitory gene $\mathrm{Bcl}-\mathrm{xL}$ of the $\mathrm{Bcl}$ 2 family, and attenuated histopathological lesions compared with nonpreconditioned I/R rats. Interestingly, after propofol infusion, mRNA expression of $\mathrm{Bcl}-\mathrm{xL}$ showed moderate upregulation, but Bax was greatly downregulated. Consequently, the ratio between anti- and proapoptotic genes 


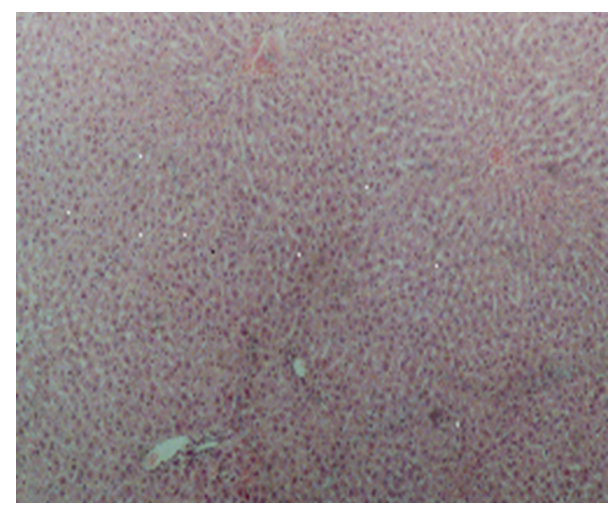

(a)

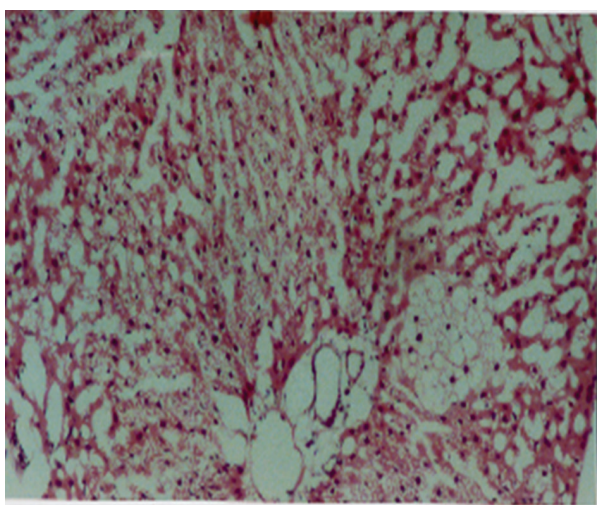

(c)

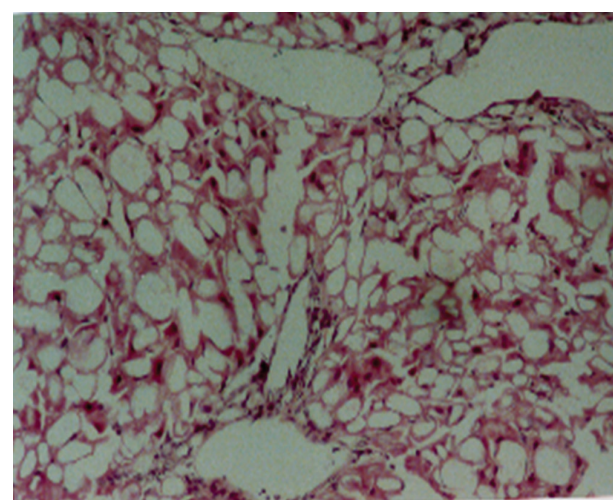

(b)

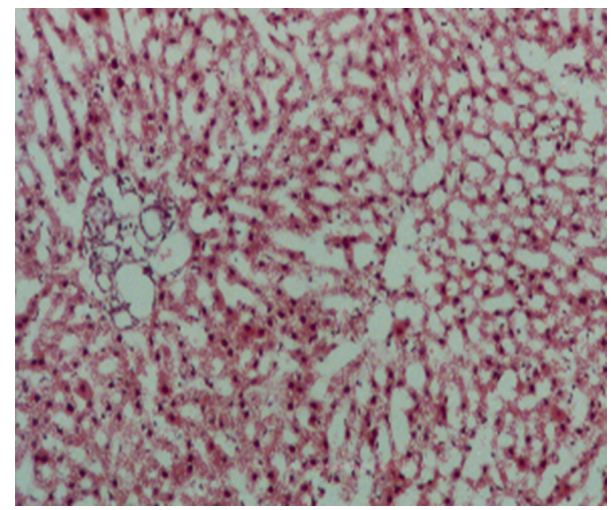

(d)

FIGURE 6: histopathological changes in liver isolated from different groups (H-E, X 100). (a) Sham-operated group showing normal liver structure. (b) I/R group showing sinusoidal congestion, fatty changes, and areas of focal necrosis. (c) I/R propofol $10 \mathrm{mg} / \mathrm{kg} / \mathrm{h}$ group showing congestion, fatty changes, and cytoplasmic vacuolation. (d) I/R propofol $20 \mathrm{mg} / \mathrm{kg} / \mathrm{h}$ group showing congestion, fatty changes, and cytoplasmic vacuolation.

was considerably increased. These results are in agreement with those of Ye et al., [17], who showed that propofol infusion can attenuate hepatic I/R injury in rabbits. Similar protective effects on liver with reduced lipid peroxidation have been observed in patients undergoing liver surgery [28]. Also, propofol was shown to suppress hepatic I/R-induced apoptosis by upregulating Bcl-2 and downregulating Bax and caspase-3 expression in rats [29]. Moreover, propofol was found to protect hepatic cells from hydrogen peroxide$\left(\mathrm{H}_{2} \mathrm{O}_{2}-\right)$ induced apoptosis in vitro via activating extracellular signal-regulated kinases pathway and further suppressing Bad and Bax expression [30]. It has been reported that multiple protein kinases, including MAPKs, may phosphorylate Bcl-2 and stimulate its antiapoptotic function [31]. Some studies showed that interventions such as overexpression of Bcl-2 can prevent both apoptotic and necrotic cell death [32]. Moreover, a recent study found that propofol reduced TNFinduced apoptosis by affecting Bcl-2 and Bax expression [33].

However, current results are not in full agreement with previous studies, which yielded conflicting data regarding the effects of propofol on the liver under oxidative stress. Although Shimono et al., [16], found no evidence for a beneficial effect of propofol against liver hypoxia/reoxygenation injury in rat liver slices, propofol was shown to protect suspensions of isolated rat hepatocytes from an oxidant insult [12]. Moreover, Lee et al., [34], found that propofol, but not pentobarbital, exerts a protective effect on hepatocytes exposed to $\mathrm{H}_{2} \mathrm{O}_{2}$ oxidant stress in vitro. Reasons for these discrepancies may include the use of different experimental models. For example, liver slices are multilayered and include not only hepatocytes but also other cell types (such as Kupffer cells and neutrophils) that inhibit the antioxidant effects of propofol [16]. Moreover, the in vitro environment cannot completely imitate in vivo conditions, which may mask the role of propofol. The lack of a protective effect of propofol in an in vitro liver model might be because of the use of oxygen during its own metabolism, resulting in an oxygenation debt. In contrast, in vivo, the increase in hepatic oxygen consumption by propofol is fully compensated for by an increased oxygen supply owing to increased hepatic blood flow in rat [35] and rabbit models [36]. There is good evidence that vasodilators protect against I/R injury by improving hepatic blood flow and thus maintaining an oxygen balance and energy metabolism [37]. Therefore, it is hypothesized that in vivo propofol would have a hepatoprotective effect on I/R injury.

The mechanism underlying hepatoprotective effect of propofol may be explained by the results of previous studies demonstrating that propofol could produce nonanesthetic 
organ protective effects, including the reduction of free radical generation and radical scavenging [12], inhibitory effects on calcium channels and reducing intracellular calcium overload [38], reducing inflammatory cell chemotaxis [39], and improving microcirculation via the reported propofolinduced nitric oxide (NO) and vasodilatory prostanoid production [40]. The antioxidant activity of propofol may mediate its potential role to modulate apoptosis [41]. Also, reduction of TNF- $\alpha$ and caspase-3 levels, with increased Bcl$\mathrm{xL} / \mathrm{Bax}$ ratio observed in this study, probably contributed to the protective effect of propofol on hepatic I/R in rats.

Optimum dosage required for tissue protection has been incompletely explored and is likely significantly tissue specific. Since it has shown that propofol increased hepatic blood flow in a dose dependent manner [35], the hepatoprotective effect of propofol may be also dose-dependent. Lee et al., [34], found that propofol has a protective effect on hepatocytes in a clinically relevant concentrations of $1-50 \mu \mathrm{M}$, because peak plasma concentrations of propofol are reportedly $40-60 \mu \mathrm{M}$ $(7.12-10.68 \mu \mathrm{g} / \mathrm{mL})$ at anesthesia induction and $10-25 \mu \mathrm{M}$ $(1.78-4.45 \mu \mathrm{g} / \mathrm{mL})$ during anesthesia maintenance [42]. de la Cruz et al., [13], reported that $50-300 \mu \mathrm{M}$, but not $10 \mu \mathrm{M}$, propofol had significant effects on all the oxidative-stress variables they studied in rat brain slices. Kokita et al., [14], reported that propofol 25 and $50 \mu \mathrm{M}$ both improved the recovery of mechanical function and energy state in $\mathrm{I} / \mathrm{R}$ rat hearts and dose dependently inhibited lipid peroxidation in the rat heart. Navapurkar et al., [12], reported that $28 \mu \mathrm{M}$ propofol protected rat hepatocytes from an oxidant stress sufficient to cause cell death at one hour. In the present study, clinically relevant doses of propofol $(10$ or $20 \mathrm{mg} / \mathrm{kg} / \mathrm{h}$ ) produced similar hepatoprotective effect, although larger dose produced more marked reduction in TNF- $\alpha$ level. This conforms with the results of Ye et al., [17], who reported that propofol infusion can attenuate hepatic I/R injury in rabbits, and this effect was not affected by duration of propofol infusion for 10, 30, or $60 \mathrm{~min}$ before the ischemic insult. Further study will be needed to clarify whether larger doses of propofol than those used in our study might have a more beneficial effect against I/R injury in the liver.

In conclusion, intravenous infusion of propofol, at a dose of 10 or $20 \mathrm{mg} / \mathrm{kg} / \mathrm{h}$ starting $30 \mathrm{~min}$ before ischemia, is effective in reducing hepatic I/R injury and decreasing associated cellular apoptosis, with no observed dose-dependent effects. Based on these results, propofol antioxidant and anti-inflammatory activity may be involved in its beneficial effects in hepatic I/R injury. These results may spark future investigations using propofol as a potential hepatoprotective anesthetic in liver surgery. In comparison with established methods of liver preconditioning, such as ischemic preconditioning, propofol might have an advantage of being not only needed to achieve liver protection but also used for the anesthesia during liver surgical interventions.

\section{Conflict of Interests}

The authors declare that there is no conflict of interests that could be perceived.

\section{Acknowledgment}

The authors would like to thank Dr. Mohammad AlMesallamany, for kind assistance in the histopathological evaluation.

\section{References}

[1] N. C. Teoh and G. C. Farrell, "Hepatic ischemia reperfusion injury: pathogenic mechanisms and basis for hepatoprotection," Journal of Gastroenterology and Hepatology, vol. 18, no. 8, pp. 891-902, 2003.

[2] P.-A. Clavien, H. Petrowsky, M. L. DeOliveira, and R. Graf, "Strategies for safer liver surgery and partial liver transplantation," The New England Journal of Medicine, vol. 356, no. 15, pp. 1545-1559, 2007.

[3] V. Kohli, M. Selzner, J. F. Madden, R. C. Bentley, and P.A. Clavien, "Endothelial cell and hepatocyte deaths occur by apoptosis after ischemia-reperfusion injury in the rat liver," Transplantation, vol. 67, no. 8, pp. 1099-1105, 1999.

[4] A. Saraste and K. Pulkki, "Morphologic and biochemical hallmarks of apoptosis," Cardiovascular Research, vol. 45, no. 3, pp. 528-537, 2000.

[5] J. S. Gujral, T. J. Bucci, A. Farhood, and H. Jaeschke, "Mechanism of cell death during warm hepatic ischemia-reperfusion in rats: apoptosis or necrosis?" Hepatology, vol. 33, no. 2, pp. 397405, 2001.

[6] J. Bowes and C. Thiemermann, "Effects of inhibitors of the activity of poly (ADP-ribose) synthetase on the liver injury caused by ischaemia-reperfusion: a comparison with radical scavengers," British Journal of Pharmacology, vol. 124, no. 6, pp. 1254-1260, 1998.

[7] J. M. Adams and S. Cory, "The Bcl-2 protein family: arbiters of cell survival," Science, vol. 281, no. 5381, pp. 1322-1326, 1998.

[8] L. M. Colletti, D. G. Remick, G. D. Burtch, S. L. Kunkel, R. M. Strieter, and D. A. Campbell Jr., "Role of tumor necrosis factor- $\alpha$ in the pathophysiologic alterations after hepatic ischemia/reperfusion injury in the rat," Journal of Clinical Investigation, vol. 85, no. 6, pp. 1936-1943, 1990.

[9] H. A. Rüdiger and P. Clavien, "Tumor necrosis factor $\alpha$, but not Fas, mediates hepatocellular apoptosis in the murine ischemic liver," Gastroenterology, vol. 122, no. 1, pp. 202-210, 2002.

[10] D. Takizawa, E. Sato, H. Hiraoka et al., "Changes in apparent systemic clearance of propofol during transplantation of living related donor liver," British Journal of Anaesthesia, vol. 95, no. 5, pp. 643-647, 2005.

[11] J. S. Ko, M. S. Gwak, S. J. Choi et al., "The effects of desflurane and propofol-remifentanil on postoperative hepatic and renal functions after right hepatectomy in liver donors," Liver Transplantation, vol. 14, no. 8, pp. 1150-1158, 2008.

[12] V. U. Navapurkar, J. N. Skepper, J. G. Jones, and D. K. Menon, "Propofol preserves the viability of isolated rat hepatocyte suspensions under an oxidant stress," Anesthesia and Analgesia, vol. 87, no. 5, pp. 1152-1157, 1998.

[13] J. P. de la Cruz, M. A. Villalobos, G. Sedeño, and F. Sánchez de la Cuesta, "Effect of propofol on oxidative stress in an in vitro model of anoxia- reoxygenation in the rat brain," Brain Research, vol. 800, no. 1, pp. 136-144, 1998.

[14] N. Kokita, A. Hara, Y. Abiko, J. Arakawa, H. Hashizume, and A. Namiki, "Propofol improves functional and metabolic recovery in ischemic reperfused isolated rat hearts," Anesthesia and Analgesia, vol. 86, no. 2, pp. 252-258, 1998. 
[15] O. Aldemir, H. Celebi, C. Cevik, and E. Duzgun, "The effects of propofol or halothane on free radical production after tourniquet induced ischaemia-reperfusion injury during knee arthroplasty," Acta Anaesthesiologica Scandinavica, vol. 45, no. 10, pp. 1221-1225, 2001.

[16] H. Shimono, T. Goromaru, Y. Kadota, T. Tsurumaru, and Y. Kanmura, "Propofol displays no protective effect against hypoxia/reoxygenation injury in rat liver slices," Anesthesia and Analgesia, vol. 97, no. 2, pp. 442-448, 2003.

[17] L. Ye, C.-Z. Luo, S. A. McCluskey, Q.-Y. Pang, and T. Zhu, "Propofol attenuates hepatic ischemia/reperfusion injury in an in vivo rabbit model," Journal of Surgical Research, vol. 178, no. 2, pp. e65-e70, 2012.

[18] A. Koo, H. Komatsu, G. Tao, M. Inoue, P. H. Guth, and N. Kaplowitz, "Contribution of no-reflow phenomenon to hepatic injury after ischemia-reperfusion: evidence for a role for superoxide anion," Hepatology, vol. 15, no. 3, pp. 507-514, 1992.

[19] P. Chomczynski and N. Sacchi, "Single-step method of RNA isolation by acid guanidinium thiocyanate-phenol-chloroform extraction," Analytical Biochemistry, vol. 162, no. 1, pp. 156-159, 1987.

[20] C.-J. Lee, Y.-M. Subeq, R.-P. Lee, W.-T. Wu, and B.-G. Hsu, "Low-dose propofol ameliorates haemorrhagic shock-induced organ damage in conscious rats," Clinical and Experimental Pharmacology and Physiology, vol. 35, no. 7, pp. 766-774, 2008.

[21] A. B. Lentsch, H. Yoshidome, W. G. Cheadle, F. N. Miller, and M. J. Edwards, "Chemokine involvement in hepatic ischemia/reperfusion injury in mice: roles for macrophage inflammatory protein-2 and Kupffer cells," Hepatology, vol. 27, no. 2, pp. 507-512, 1998.

[22] K.-C. Chan, C.-J. Lin, P.-H. Lee et al., "Propofol attenuates the decrease of dynamic compliance and water content in the lung by decreasing oxidative radicals released from the reperfused liver," Anesthesia and Analgesia, vol. 107, no. 4, pp. 1284-1289, 2008.

[23] G.-H. Hu and X.-S. Lü, "Effect of normothermic liver ischemic preconditioning on the expression of apoptosis-regulating genes C-jun and Bcl-XL in rats," World Journal of Gastroenterology, vol. 11, no. 17, pp. 2579-2582, 2005.

[24] S. W. Fesik and Y. Shi, "Controlling the caspases," Science, vol. 294, no. 5546, pp. 1477-1478, 2001.

[25] A. Hartkorn, F. Hoffmann, H. Ajamieh et al., "Antioxidant effects of xanthohumol and functional impact on hepatic ischemia-reperfusion injury," Journal of Natural Products, vol. 72, no. 10, pp. 1741-1747, 2009.

[26] D. Wallach, A. V. Kovalenko, E. E. Varfolomeev, and M. P. Boldin, "Death-inducing functions of ligands of the tumor necrosis factor family: a Sanhedrin verdict," Current Opinion in Immunology, vol. 10, no. 3, pp. 279-288, 1998.

[27] C.-M. Tsao, S.-T. Ho, A. Chen, J.-J. Wang, S.-K. Tsai, and C.C. Wu, "Propofol ameliorates liver dysfunction and inhibits aortic superoxide level in conscious rats with endotoxic shock," European Journal of Pharmacology, vol. 477, no. 2, pp. 183-193, 2003.

[28] L.-N. Lin, W.-T. Wang, J.-Z. Wu, Z.-Y. Hu, and K.-J. Xie, "Protective effect of propofol on liver during ischemia-reperfusion injury in patients undergoing liver surgery," Zhongguo Wei Zhong Bing ji Jiu yi Xue, vol. 16, no. 1, pp. 42-44, 2004.

[29] X. Shen, G. Zhao, R. Wang, T. Liu, and L. Liu, "Protective effect of propofol and resveratrol pretreatment against hepatocyte apoptosis in rats with hepatic ischemia-reperfusion injury," Nan Fang Yi Ke Da Xue Xue Bao, vol. 33, no. 1, pp. 80-85, 2013.
[30] H. Wang, Z. Xue, Q. Wang, X. Feng, and Z. Shen, "Propofol protects hepatic 102 cells from hydrogen peroxide-induced apoptosis via activation of extracellular signal-regulated kinases pathway," Anesthesia and Analgesia, vol. 107, no. 2, pp. 534-540, 2008.

[31] D. M. Hockenbery, Z. N. Oltvai, X.-M. Yin, C. L. Milliman, and S. J. Korsmeyer, "Bcl-2 functions in an antioxidant pathway to prevent apoptosis," Cell, vol. 75, no. 2, pp. 241-251, 1993.

[32] X. Deng, F. Gao, and W. S. May Jr., "Bcl2 retards G1/S cell cycle transition by regulating intracellular ROS," Blood, vol. 102, no. 9, pp. 3179-3185, 2003.

[33] T. Luo and Z. Xia, "A small dose of hydrogen peroxide enhances tumor necrosis factor-alpha toxicity in inducing human vascular endothelial cell apoptosis: reversal with propofol," Anesthesia and Analgesia, vol. 103, no. 1, pp. 110-116, 2006.

[34] J. Y. Lee, J.-W. Shin, E. H. Lee, S.-H. Baek, S. W. Ku, and J. U. Kim, "Comparison of the effects of propofol and pentobarbital on hydrogen peroxide-stimulated hepatic SNU761 cells," Korean Journal of Anesthesiology, vol. 58, no. 3, pp. 277-282, 2010.

[35] F. J. Carmichael, M. W. Crawford, N. Khayyam, and V. Saldivia, "Effect of propofol infusion on splanchnic hemodynamics and liver oxygen consumption in the rat: a dose-response study," Anesthesiology, vol. 79, no. 5, pp. 1051-1060, 1993.

[36] T. Zhu, Q. Pang, S. A. McCluskey, and C. Luo, "Effect of propofol on hepatic blood flow and oxygen balance in rabbits," Canadian Journal of Anesthesia, vol. 55, no. 6, pp. 364-370, 2008.

[37] S. Chin, M. Ikeda, M. Ozaki, and S. Kameoka, "Protective effect of diltiazem on hepatic ischemia-reperfusion injury in rats by improving liver tissue blood flow," Transplantation Proceedings, vol. 37, no. 10, pp. 4556-4559, 2005.

[38] Y.-C. Li, P. Ridefelt, L. Wiklund, and G. Bjerneroth, "Propofol induces a lowering of free cytosolic calcium in myocardial cells," Acta Anaesthesiologica Scandinavica, vol. 41, no. 5, pp. 633-638, 1997.

[39] T. Nagata, M. Kansha, K. Irita, and S. Takahashi, "Propofol inhibits FMLP-stimulated phosphorylation of p42 mitogenactivated protein kinase and chemotaxis in human neutrophils," British Journal of Anaesthesia, vol. 86, no. 6, pp. 853-858, 2001.

[40] K. W. Park, H. B. Dai, E. Lowenstein, and F. W. Sellke, "Propofolassociated dilation of rat distal coronary arteries is mediated by multiple substances, including endothelium-derived nitric oxide," Anesthesia and Analgesia, vol. 81, no. 6, pp. 1191-1196, 1995.

[41] E. S. Osman, H. F. Khafagy, Y. M. Samhan et al., "In vivo effects of different anesthetic agents on apoptosis," Korean Journal of Anesthesiology, vol. 63, no. 1, pp. 18-24, 2012.

[42] Y. U. Adachi, M. Satomoto, H. Higuchi, and K. Watanabe, "Rapid fluid infusion therapy decreases the plasma concentration of continuously infused propofol," Acta Anaesthesiologica Scandinavica, vol. 49, no. 3, pp. 331-336, 2005. 


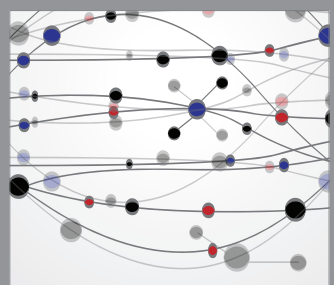

The Scientific World Journal
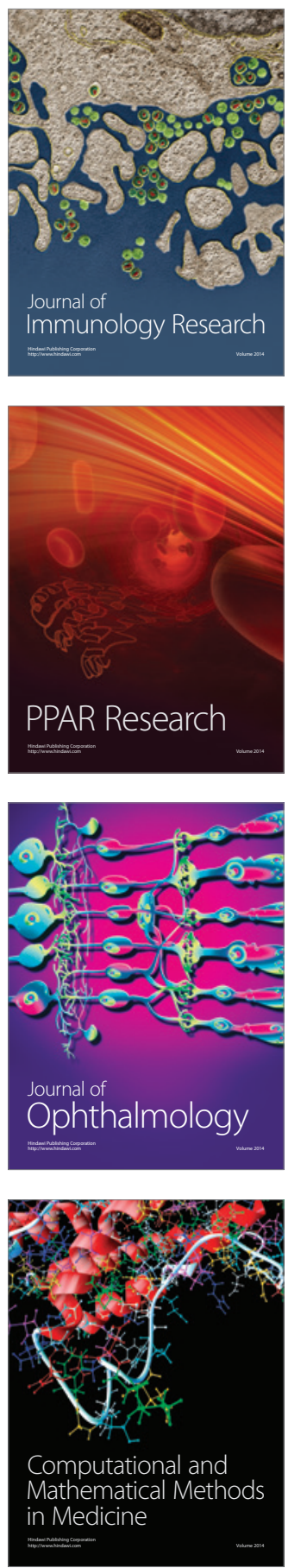

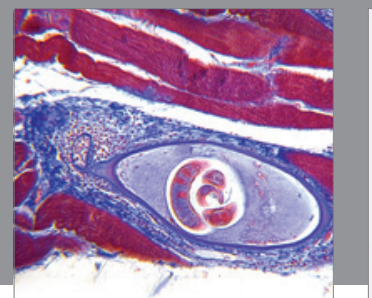

Gastroenterology

Research and Practice
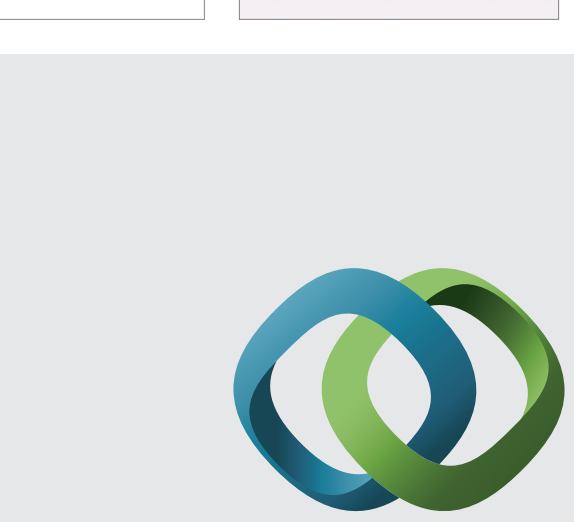

\section{Hindawi}

Submit your manuscripts at

http://www.hindawi.com
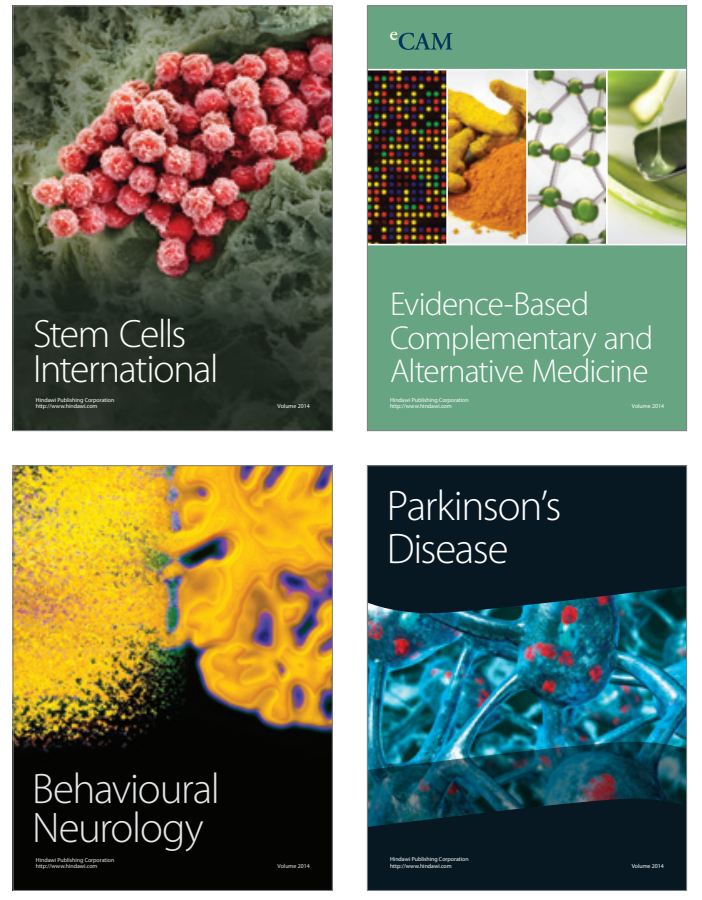
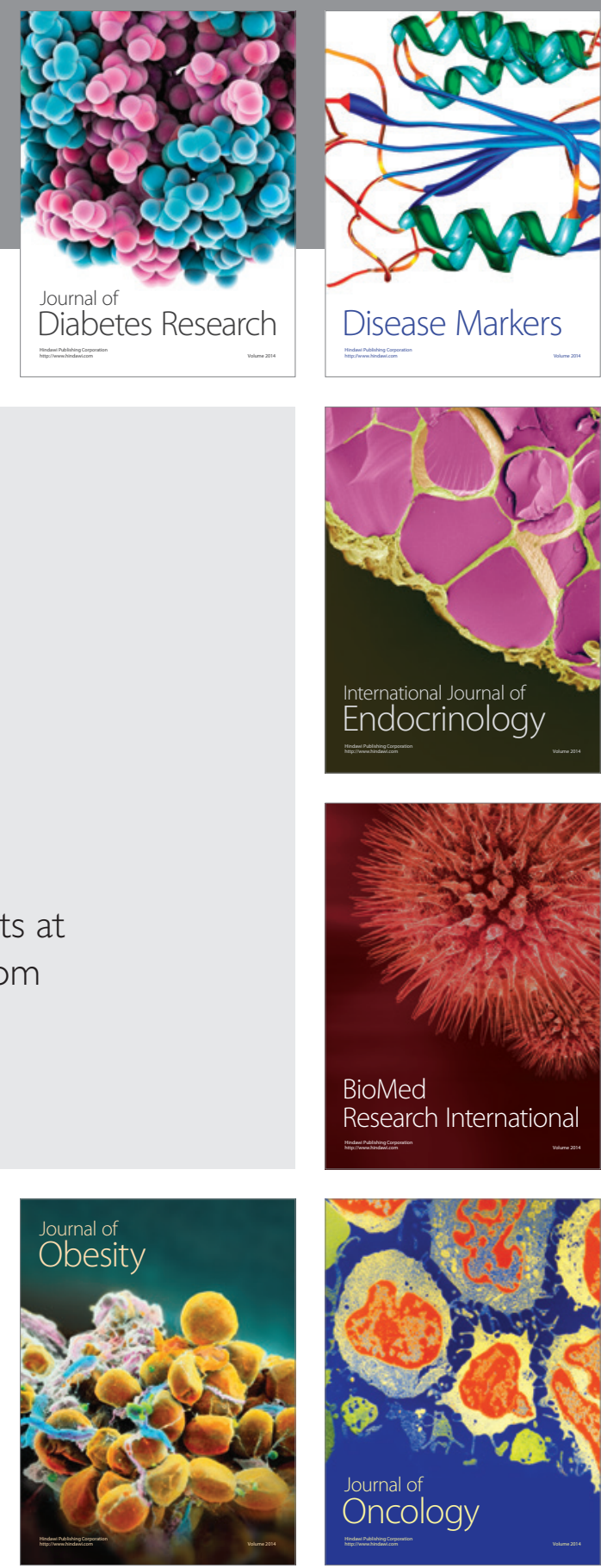

Disease Markers
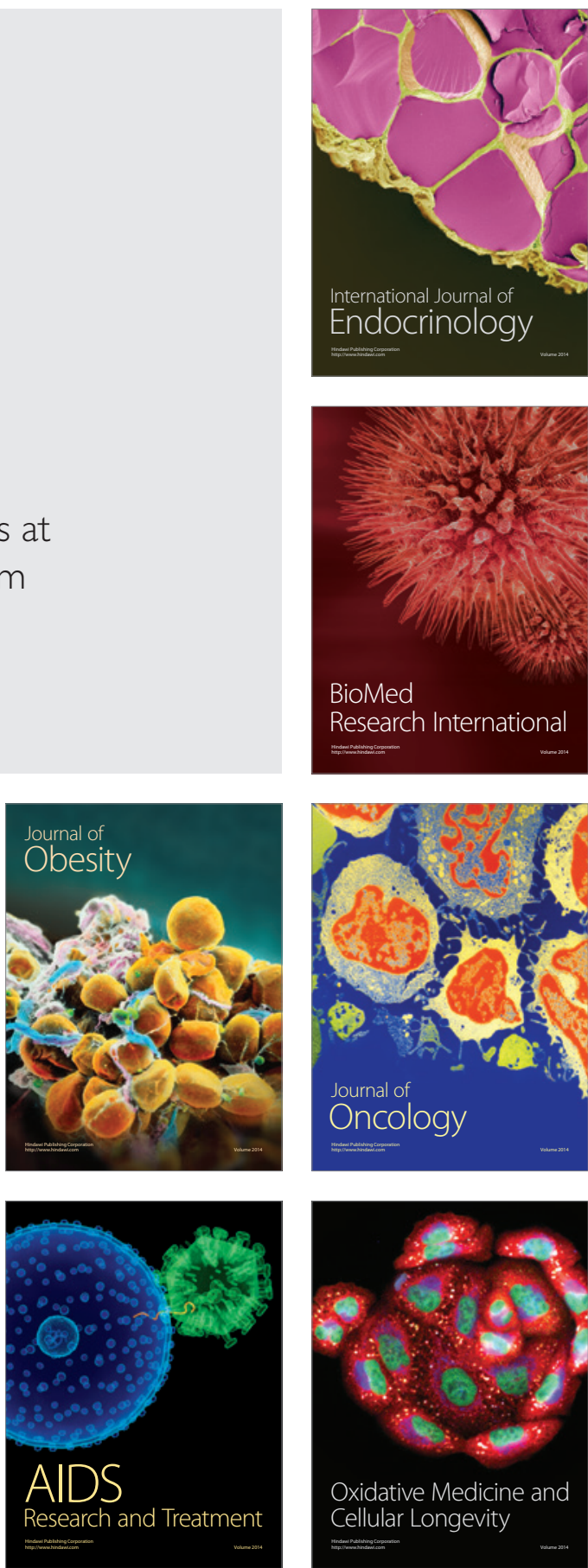